Article

\title{
Sustainability of Livestock Farming in South Africa. Outlook on Production Constraints, Climate-Related Events, and Upshot on Adaptive Capacity
}

\author{
Oluwaseun Samuel Oduniyi *(D), Theresa Tendai Rubhara and Michael Akwasi Antwi \\ Department of Agriculture and Animal Health, University of South Africa, Roodepoort 1709, South Africa; \\ erubhatt@unisa.ac.za (T.T.R.); antwima@unisa.ac.za (M.A.A.) \\ * Correspondence: eodunios@unisa.ac.za
}

Received: 9 February 2020; Accepted: 28 February 2020; Published: 25 March 2020

check for updates

\begin{abstract}
The practice of pasture-based livestock farming systems in South Africa is susceptible to climate-related events, low production output, income fluctuation, and by extension poor adaptive capacity. Understanding the importance and gravity of sustainable livestock farming through adaptive capacity has been identified as a tool to cope in the face of the climate-related event which extends to production output. It is to this end, that the study explored the adaptive capacity and the socioeconomic determinants that influence this capacity used by the pasture-based livestock farmers in the study area. Random sampling technique was used to select a sample of 277 pasture-based livestock farmers in the study area from and their responses concerning on demography, farm-based characteristics, production constraints and adaptive capacity were used. Data were analyzed, in which the descriptive statistics, composite scores, and the extended ordered probit model were used to establish the results. The findings revealed the adaptive capacity score of low, moderate, and high to be $40.1 \%, 43.7 \%$, and $16.2 \%$ respectively. Correspondingly, the model estimate revealed the significant factors that affect the adaptive capacity to include: the use of labor $(p<0.05)$, other sources of income $(p<0.05)$. Conversely, the age of the farmers $(p<0.05)$ and landowners $(p<0.01)$ was found significant but had a negative relationship to adaptive capacity. By implication, the study concluded that there is a need for fruitions of policies that support farmers' socioeconomic behavior to engage more in adaptive capacity and to improve the Sustainable Development Goals of the united nation as well as vision 2030 of the National Development Plan.
\end{abstract}

Keywords: pasture-based livestock farming system; adaptive capacity; production constraints; climate-related events; composite score; extended ordered probit; North West Province

\section{Introduction}

Over the centuries, livestock has formed the basis of human wellbeing through its contribution to the household economy, social status and food security [1]. As highlighted by [2], global livestock farming systems have evolved since the $18^{\text {th }}$ century from agro-pastoralism through to the intensification in the 21st century. However, in developing countries, there exists a thin line between different types of livestock production systems [3]. Sustainability issues have been raised in livestock production as the global demand for protein-rich diets is forecasted to increase [4], amidst production challenges which are also exacerbated by climate change negative impacts $[5,6]$. The demand for livestock products has been fostered by an upsurge in the middle class in developing countries and an increase in the global population [4].

The livestock sector is a major consumer of the natural resources with approximately $80 \%$ of the agricultural land used for grazing and $8 \%$ of water consumption is for livestock systems [6]. 
Therefore, in as much as livestock systems are likely to suffer from climate change impacts, they are also considered contributors to the subject. Life cycle assessment studies have indicated that cattle production systems contribute to global warming (as a result of increased carbon dioxide and methane emissions) water depletion, contamination of water resources, and land pollution [7,8]. Apparently, industrialized farming system such as intensive beef production has a more carbon footprint and methane gas than the free-range or pasture led system [3].

By definition, sustainability in the livestock production sector relates to the ability of the system to meet the current demand for livestock products without jeopardizing future generations' use of resources and minimizing negative externalities [9]. Based on this premise, in order for the livestock systems to be considered sustainable, they should be able to meet the current and long-run economic, social and environmental obligations.

\section{Contextual Background}

In South Africa, $80 \%$ of the agricultural land is suitable for livestock production with the sector contributing approximately $40 \%$ to the agricultural income [10]. A dual system exists in the livestock farming sector with a highly commercialized system at one end and the subsistence on the other end. Cattle are the major livestock activity in the country in both commercial and smallholder farms. Cattle production in South Africa is more concentrated in the Eastern Cape, KwaZulu Natal, Free State, and Northwest [11]. Beef cattle account for approximately $80 \%$ of the national herd with dairy accounting for $20 \%$. Approximately $60 \%$ of the beef cattle in South Africa are owned by commercial farmers and $40 \%$ by the emerging sector [11]. Three main beef production systems are common in the country: the intensive, semi extensive, and extensive production. The intensive production system ensures that specialists undertake the finishing stages of beef cattle and this is usually done in the feedlot. With clearly defined stages of production, feeding is monitored to produce the required weight in animals in the shortest period.

The primary production involves grazing animals on pastures and secondary production which requires finishing off of animals in the feedlot [10]. The bulk of the communal farmers allow animals to freely graze hence primary production and secondary production activities are combined [1]. Such systems are often referred to as extensive. However, sometimes there are overlaps between the production systems. Following [12], a more precise method of defining the production system is by what the animals eat and where they sleep. Production systems that allow the animals to forage their food more often than not and spend much of their lifecycle outside are referred to as pasture-based. The defining characteristic in pasture led systems is that supplementation of feed is rare and only temporary shelter is provided. Whilst pasture led systems in the industrialized sector are a result of consumer-driven demand for naturally fed animals, in the developing countries it is usually associated with a lack of resources for intensification therefore common in the smallholder sector [12]. In the context of this study, a pasture led production system will be used synonymously with extensive production.

Land redistribution schemes in South Africa has birthed a group of farmers known as emerging farmers. This emerging sector consists of land reform beneficiaries who have been given institutional support such as improved access to credit, extension and land rights in the bid to transform them to commercialized farmers [13]. The emerging farmers together with the communal farmers in South Africa constitute the smallholder section. In contrast to the commercial sector which is characterized by high levels of productivity and use of sophisticated machinery, the smallholder sector is often allied to a lack of access to adequate market facilities, high labor-intensity with low farm capital investment and little division of labor [14]. Cattle offtake in the smallholder sector is as low as $9 \%$ as compared to $30 \%$ in the commercial sector [15]. The problems facing smallholder farmers in Africa are complex and range from a lack of institutional support mechanisms to specific farmer related challenges.

The land issue has been at the center of public debate in the past decade, with smallholder farmers incapacitated by a lack of land rights and access to adequate agricultural land [15]. Ref [14], highlighted 
a lack of investment, poor access to extension, lack of working capital and poor livestock management practices as the major constrains limiting emerging farmers from advancing to commercialized production in Limpopo province of South Africa. Similarly, Ref[13], indicated that in livestock systems, inadequate knowledge of livestock and pasture management and decrease in veld quality as a result of climate variability are the core factors that need to be addressed to improve sustainability in extensive livestock production systems.

The changing environmental, social, and economic context over time demands that livestock producers be more innovative. Environmental sustainability debates in cattle production are centered on the impacts caused by climate change and life cycle assessments of the sector. The authors of [5] projected that by 2020 in Africa, over 75 million people would be exposed to climate variability effects and extreme weather conditions such as drought, floods, and extremely hot conditions. The vulnerability of the agricultural sector arises from its sensitivity to rainfall and temperature changes. Generally, in Southern Africa, high incidences of drought, high temperatures, and unreliable rainfall have been experienced in the past years [16]. The region is considered as arid as it receives poor spatial rainfall distribution therefore water insecurity is a common problem [17]. Increased temperatures as a result of global warming effects are more detrimental in mixed farming systems and pasture led systems rather than industrialized livestock systems.

Though extreme cases of climate change can be predicted across different regions, adaptation measures may lower the impact $[9,16,18,19]$. Adaptation refers to practices applied to a system in response to predicted shocks or stresses to reduce harm and vulnerability from the outcome of such occurrences [20]. In climate-related events, the adaptive capacity assesses the range of activities that can be utilized to cope with the negative impacts of climate change or climate variability. Adaptation targets a specific system and is based on a local to regional intervention whereas mitigation broadly targets all systems in a global context [20]. Climate variability poses a serious strain on the smallholder production systems which are already operating under a limited resource base. In pasture led systems, in particular, climate variability poses a severe threat of reducing the quality and quantity of forage in the arid to semi-arid regions $[17,21]$.

The objective of this study is, therefore, to identify and analyze production constraints and climate-related events that hinder the sustainability of PLFS and determine the socio-economic factors that influence the adaptive capacity of pasture-based livestock farmers in the study area. On the backdrop of consumer preferences towards pasture led beef due to the perceived nutritional, environmental animal welfare benefits [12], this study will provide insights on improving the sustainability of pasture led system in the South African context.

\section{Materials and Methods}

\subsection{Description of the Research Area}

The study was carried out in the North West province of South Africa. The country is located on the southern tip of Africa, with a magnitude of $1,233,404 \mathrm{~km}^{2}$ and adjoined on three sides by nearly $3000 \mathrm{~km}$ of coastline, with the Indian Ocean to the east and the Atlantic Ocean to the west. There is a borderline between the country and Namibia in the north, Botswana, Zimbabwe, and Mozambique, in addition to enclosing two independent countries, the kingdoms of Lesotho and Swaziland. North West province is also referred to as Bokone Bophirima Province, a food basket of South Africa. As shown in Figure 1, the province is situated towards the western part of South Africa. It borders Limpopo to the North, Gauteng to the east, the Free State to the east and south, the Northern Cape to the south and Botswana to the west and north. Altitude ranges from 1000 to $2000 \mathrm{~m}$ above sea level. The total land area of the province covers about $116,320 \mathrm{~km}^{2}$, and it contains $9.5 \%$ of the total area of South Africa. 


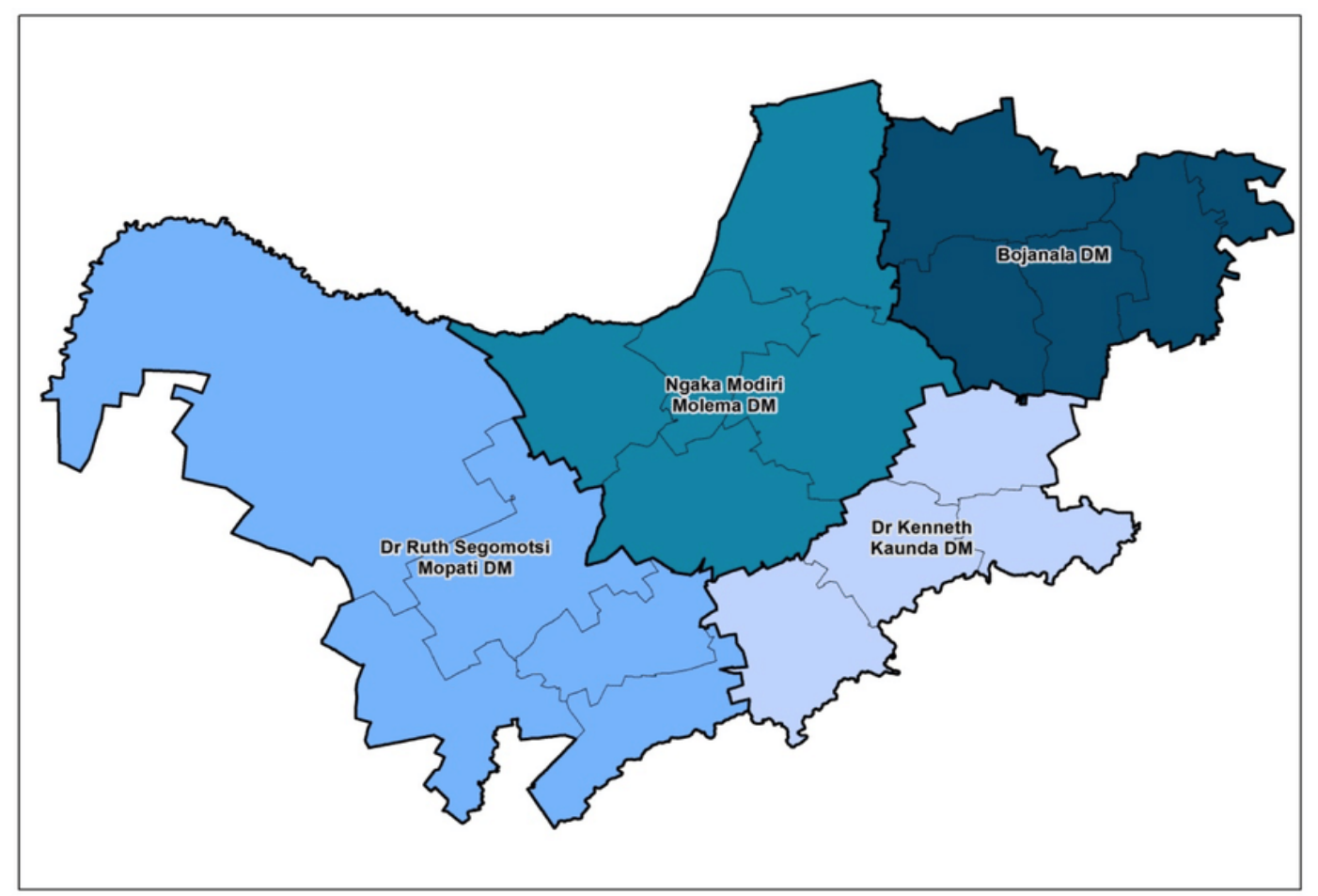

Figure 1. Map of North West municipalities, showing the study area. Source: https://municipalities.co. $\mathrm{za} /$ provinces/view/8/north-west.

The province is largely rural, while the major line of work is agriculture, though just the fifth main contributor to the GDP. North West is segmented into four district municipalities. The two districts municipalities earmarked for the study are Bojanala and Ngaka Modiri Molema (NMM), while the latter is the capital of the province, and situated at the center of the province. With the largest percentage of grazing land which justifies the concentration of cattle herds and high numbers of pasture-based livestock farmers compare to other regions, hence, Bokone Bophirima was chosen as the area for the study. In addition, Bokone Bophirima is identified for cattle farming with the largest herds of cattle found in Steelband.

\subsection{Data Collection}

Primary data were collected from the cattle farmers through an interview schedule using a semi-structured questionnaire, which was validated by two experts in the department of agricultural economics. The questionnaire was subdivided into sections based on the objectives of the study. A reliability test was done on the research instrument. The Pearson product-moment correlation method and split-half technique were adopted to ascertain the regularity of the instrument. A list of registered cattle farmers was obtained from the Provincial Department of Agriculture and Rural Development. The representative sample size was determined using Slovin's formula, as given in the Equation (1), afterward, questionnaires totaling 277 were doled out to the cattle farmers in the district via random sampling technique. Following [22] postulations, this was realized by adopting a quantitative model as illustrated below:

$$
\mathrm{n}=\frac{N}{1+\mathrm{N}(\mathrm{e})^{2}}
$$

where $\mathrm{n}$ is the sample size,

$\mathrm{N}=$ total population of cattle farmers in the two districts municipalities

$\mathrm{e}=$ maximum variability or margin of error $(\mathrm{MoE})$. This is estimated at $5 \%(0.05)$, 
$1=$ probability of the event occurring,

$277=$ the number of respondents sampled or sample size.

\subsection{Data Analysis}

The data for this study was based on cross-sectional data which were collected from the aforementioned study area in the year 2019. Data were coded and subjected to analysis using statistical software (XLSTAT and STATA version 15). Descriptive and inferential statistics were employed. Descriptive statistics such as frequency counts, median, mean values, variance, and standard deviation were used to describe the demography, farm-based characteristics, production constraints of PLFS. While the inferential statistics used were multicollinearity, to ensure the absence of collinearity among the variables, correlation matrix, principal component analysis to convert a set of observations of possibly correlated variables into a set of values of linearly uncorrelated variable, in order words it was used to identify and analyzed production constraints and climate-related events that hinder the sustainability of PLFS. Lastly, the extended ordered probit regression model was used to model and determine the socio-economic factors that influence the adaptive capacity of pasture-based livestock farmers in the study area.

\subsection{Empirical Model}

Principal component analysis (PCA): $P C A$ is an orthogonal transformation method of converting a set of possibly correlated observations into an uncorrelated linear set of variables. In dealing with many sets of variables, firstly, the dispersion matrix may be too much to study and interpret effectively, secondly, there may occur many pairwise correlations between the variables to consider, then, it is, therefore, necessary to use $P C A$ to reduce the number of variables to a few combinations of data that are linear and interpretable in nature. The same each linear combination agrees to a principal component, in which the conversion or the transformation is presented in a way that the $P C_{1}$ has the highest variance possible under the constraint that it is orthogonal to the preceding components. However, the data are analyzed to give eigenvectors, eigenvalues, and variability. Eigenvectors and eigenvalues exist in pairs and every eigenvector has a corresponding eigenvalue. An eigenvector is a direction while an eigenvalue is a number that shows how much variance there is in the data in that direction [23].

The result obtained from the $P C A$ is usually expressed in terms of factor loadings. The PCA that has an eigenvalue lower than 1 is considered inappropriate and contains less information which cannot be retained, while the PCA with eigenvalue higher than 1 is retained. Mathematically, we are transforming a set of variables (see Equation (1)) into new uncorrelated variables called principal components (see Equation (2)) that are linear combinations of original variables set.

$$
\begin{gathered}
X_{j}(j=1,2 \ldots \ldots \ldots, n) \\
P C I(I=1,2 \ldots \ldots, n)
\end{gathered}
$$

Consider the linear combinations

$$
\begin{aligned}
P C_{1} & =a_{11} X_{1}+a_{12} X_{2}+\ldots \ldots \ldots+a_{1 K} X_{K} \\
P C_{2} & =a_{21} X_{1}+a_{22} X_{2}+\ldots \ldots \ldots .+a_{2 K} X_{K} \\
P C_{3} & =a_{31} X_{1}+a_{32} X_{2}+\ldots \ldots \ldots .+a_{3 K} X_{K} \\
P C_{K} & =a_{K 1} X_{1}+a_{K 2} X_{2}+\ldots \ldots \ldots .+a_{K K} X_{K}
\end{aligned}
$$

where $P C_{1}=$ the $i$ th principal component, $a_{i j}=$ component loadings (coefficients) and $X_{j}=$ original variables. 
In a nutshell, several variables that are considered constraints to livestock production, as well as climate-related events in the study area were used for the $P C A$ where five-factor loadings were retained and transformed into a new set of variables which represents constraints to livestock production amidst of climate-related events. Therefore, the linear combinations give rise to first principal component $\left(P C_{1}\right)$ accounts for the maximum possible proportion of the total variation in the $\mathrm{Xj}^{\prime} \mathrm{s}$, the second principal component $\left(P C_{2}\right)$ accounts for the maximum of the remaining variation (variance) in the $\mathrm{Xj}_{\mathrm{j}} \mathrm{s}$ and so on. In this manner, we have var $\left(P C_{1}\right) \geq \operatorname{var}\left(P C_{2}\right) \geq \operatorname{var}\left(P C_{3}\right) \geq \ldots \geq \operatorname{var}\left(P C_{P}\right)$, where var $\left(P C_{1}\right)$ expresses the variance of $P C_{1}$ in the data set is measured.

Extended Regression Model (ERMs): The extended regression model was adopted because it takes care of endogenous covariates. Since the dependent variable is ordered in nature, an extended ordered probit regression model was used. The model is a generalized probit model that permits more than two discrete outcomes that are ordered. The ordered probit model is used to estimate relationships between a polytomous dependent variable that structurally orders against a set of regressor variables [24]. Firstly, the composite score was calculated from the set of questions in the questionnaire which allow the dependent variables to be categorized into three groups, namely; high adaptive capacity, moderate adaptive capacity, and low adaptive capacity. The categorizations were coded in a censoring value of 2,1 , and 0 respectively, after which an extended ordered probit regression model was employed to estimates the likelihood of socioeconomics characteristics that influence farmers' adaptive capacity to climate-related events. The model can be mathematically written as:

$$
\mathrm{y}^{*}=x^{1} \beta+e
$$

where $x$ and $\beta$ are standard variables and parameter matrices, and $e$ is a vector matrix of normally distributed error terms, and $\mathrm{y}^{*}$ is unobserved.

$$
\begin{gathered}
y=0 \text { if } y^{*} \leq 0 \\
y=1 \text { if } 0<y^{*} \leq \mu 1 \\
y=2 \text { if } \mu 1<y^{*} \leq \mu 2
\end{gathered}
$$

where $\mu 1$ and $\mu 2$ are the cut off points (intercept shifters).

The likelihood estimates of the socio-economics characteristic that influence adaptive capacity by an individual farmer are given as:

$$
\begin{gathered}
\mathrm{L}=\left[\Phi\left(0-X_{i} \beta\right)\right] \mathrm{zi}_{1}\left[\Phi\left(\mu_{1}-X_{i} \beta\right)-\Phi\left(0-X_{i} \beta\right)\right] \mathrm{zi}_{2}\left[1-\Phi\left(X_{i} \beta-\mu_{1}\right)\right] \mathrm{zi}_{3} \\
Z_{i j}=\left\{\begin{array}{c}
1 \text { if } y 1=j \\
0, \text { Otherwise for } j=0,1 \text { and } 2
\end{array}\right.
\end{gathered}
$$

\section{Results and Discussion}

Socioeconomic characteristics: The summary statistics of the farmers' demography, farm-based characteristics, and adaptive capacity profile were presented in Table 1 . This explains the descriptive statistics in which the characteristics of the group gender was found to be $90.6 \%$ for men and $9.4 \%$ for women. The summary descriptive for the explanatory variables were presented in Table 1 below. Table 2 explains the levels of adaptive capacity and their percentages. 
Table 1. Descriptive statistics.

\begin{tabular}{|c|c|c|c|c|c|c|}
\hline Variable & Minimum & Maximum & Median & Mean & Variance $(n-1)$ & $\begin{array}{c}\text { Std. } \\
\text { Deviation }\end{array}$ \\
\hline Gender & 0.000 & 1.000 & 1.000 & 0.906 & 0.085 & 0.292 \\
\hline Farming Experience & 0.000 & 23.000 & 10.000 & 9.614 & 29.267 & 5.410 \\
\hline Age & 30.000 & 69.000 & 51.000 & 50.473 & 62.779 & 7.923 \\
\hline Marital Status & 0.000 & 1.000 & 1.000 & 0.606 & 0.240 & 0.489 \\
\hline Education & 0.000 & 1.000 & 1.000 & 0.603 & 0.240 & 0.490 \\
\hline Household Dependent & 0.000 & 12.000 & 6.000 & 6.007 & 8.225 & 2.868 \\
\hline Occupation & 1.000 & 6.000 & 1.000 & 1.325 & 1.524 & 1.235 \\
\hline Other Income Source & 0.000 & 1.000 & 1.000 & 0.592 & 0.242 & 0.492 \\
\hline Labor Use & 0.000 & 3.000 & 0.000 & 0.195 & 0.549 & 0.741 \\
\hline Own the Land & 0.000 & 1.000 & 0.000 & 0.036 & 0.035 & 0.187 \\
\hline TLU & 0.000 & 775.000 & 41.000 & 69.415 & 12414.403 & 111.420 \\
\hline Income & 0.000 & $270,000.000$ & $14,000.000$ & $19,303.971$ & $677,009,730.550$ & $26,019.411$ \\
\hline Adaptive Capacity & 0.000 & 2.000 & 1.000 & 0.762 & 0.508 & 0.713 \\
\hline
\end{tabular}

Table 2. Percentage of Adaptive Capacity of Pasture-based livestock farmers.

\begin{tabular}{cc}
\hline Adaptive Capacity & Frequency (\%) \\
\hline Low adaptive capacity & $111(40.1)$ \\
Moderate adaptive capacity & $121(43.7)$ \\
High adaptive capacity & $45(16.2)$ \\
Total & $277(100)$ \\
\hline
\end{tabular}

Source: Authors' Computation, 2020.

Analysis of production constraints and climate-related events: Several variables were considered as constraints to PLFS by the farmers in the study area. Included are the climate-related variables in which the farmers attempt to foster adaptive capacity. All variables were subjected to PCA analysis to generate a new set of linear uncorrelated variables which influence PLFS in the study area. Multicollinearity test and correlation matrix were also determined as shown in Tables 3 and 4, respectively where the mean VIF was 1.705 . This shows that there was no presence of multicollinearity among the variables responsible for PLFS. Table 5 revealed the descriptive summary of the identified factors that influence pasture-based livestock production in the study area.

Table 3. Multicollinearity statistics test.

\begin{tabular}{cccc}
\hline Variables & $\mathbf{R}^{2}$ & Tolerance & VIF \\
\hline Shortage of labor $\left(\mathrm{X}_{1}\right)$ & 0.647 & 0.353 & 2.832 \\
Inadequate rainfall $\left(\mathrm{X}_{2}\right)$ & 0.669 & 0.331 & 3.022 \\
Fluctuation in the product price $\left(\mathrm{X}_{3}\right)$ & 0.500 & 0.500 & 2.000 \\
Lack of storage facilities $\left(\mathrm{X}_{4}\right)$ & 0.362 & 0.638 & 1.568 \\
Lack of fund and resources $\left(\mathrm{X}_{5}\right)$ & 0.661 & 0.339 & 2.953 \\
Lack of access to buy input $\left(\mathrm{X}_{6}\right)$ & 0.368 & 0.632 & 1.582 \\
Death of animal $\left(\mathrm{X}_{7}\right)$ & 0.234 & 0.766 & 1.306 \\
Reduction in livestock number $\left(\mathrm{X}_{8}\right)$ & 0.196 & 0.804 & 1.244 \\
Shortage of pasture $\left(\mathrm{X}_{9}\right)$ & 0.106 & 0.894 & 1.118 \\
Pest and disease $\left(\mathrm{X}_{10}\right)$ & 0.139 & 0.861 & 1.162 \\
Flood $\left(\mathrm{X}_{11}\right)$ & 0.329 & 0.671 & 1.491 \\
Drought $\left(\mathrm{X}_{12}\right)$ & 0.123 & 0.877 & 1.140 \\
Fire $\left(\mathrm{X}_{13}\right)$ & 0.239 & 0.761 & 1.314 \\
Storm $\left(\mathrm{X}_{14}\right)$ & 0.123 & 0.877 & 1.140 \\
Mean $\mathbf{V I F}$ & & & 1.705 \\
\hline
\end{tabular}

Source: Authors' Computation, 2020. 
Table 4. Correlation Matrix.

\begin{tabular}{|c|c|c|c|c|c|c|c|c|c|c|c|c|c|c|}
\hline Variables & $X_{1}$ & $X_{2}$ & $X_{3}$ & $X_{4}$ & $X_{5}$ & $X_{6}$ & $X_{7}$ & $X_{8}$ & $X_{9}$ & $X_{10}$ & $X_{11}$ & $X_{12}$ & $X_{13}$ & $\mathrm{X}_{14}$ \\
\hline$x_{1}$ & 1 & & & & & & & & & & & & & \\
\hline$x_{2}$ & 0.579 & 1 & & & & & & & & & & & & \\
\hline$x_{3}$ & 0.517 & 0.610 & 1 & & & & & & & & & & & \\
\hline$X_{5}$ & 0.353 & -0.113 & 0.196 & 0.006 & 1 & & & & & & & & & \\
\hline$x_{6}$ & 0.455 & 0.395 & 0.413 & 0.316 & 0.044 & 1 & & & & & & & & \\
\hline$x_{7}$ & 0.218 & 0.057 & 0.052 & 0.038 & 0.380 & 0.160 & 1 & & & & & & & \\
\hline$X_{8}$ & 0.238 & 0.081 & 0.103 & 0.003 & 0.375 & 0.095 & 0.180 & 1 & & & & & & \\
\hline$x_{10}$ & 0.207 & -0.002 & 0.109 & 0.099 & 0.248 & 0.062 & 0.148 & -0.013 & -0.031 & 1 & & & & \\
\hline$x_{11}$ & 0.124 & -0.125 & 0.063 & 0.008 & 0.534 & -0.033 & 0.096 & 0.219 & 0.014 & 0.115 & 1 & & & \\
\hline$x_{12}$ & 0.117 & -0.020 & -0.012 & 0.085 & 0.184 & -0.013 & 0.191 & 0.086 & 0.114 & 0.184 & -0.025 & 1 & & \\
\hline$x_{13}$ & 0.106 & -0.072 & 0.128 & -0.094 & 0.446 & -0.010 & 0.205 & 0.081 & 0.056 & 0.080 & 0.165 & 0.032 & 1 & \\
\hline $\mathrm{x}_{14}$ & 0.112 & 0.034 & 0.003 & -0.195 & 0.096 & -0.049 & -0.002 & 0.144 & 0.002 & -0.078 & 0.069 & -0.127 & 0.034 & 1 \\
\hline
\end{tabular}

Source: Authors' Computation, 2020. Note: Values in bold are different from 0 with a significance level alpha $=0.05$. 
Table 5. Descriptive statistics of the production constraints and the climate related events.

\begin{tabular}{cccccc}
\hline Variable & Minimum & Maximum & Mean & $\begin{array}{c}\text { Variance } \\
(\mathbf{n}-\mathbf{1})\end{array}$ & Std. Deviation \\
\hline Shortage of labor $\left(\mathrm{X}_{1}\right)$ & 1.000 & 3.000 & 2.430 & 0.478 & 0.691 \\
Inadequate rainfall $\left(\mathrm{X}_{2}\right)$ & 1.000 & 3.000 & 2.347 & 0.814 & 0.902 \\
Fluctuation in the product price $\left(\mathrm{X}_{3}\right)$ & 1.000 & 3.000 & 1.834 & 0.320 & 0.566 \\
Lack of storage facilities $\left(\mathrm{X}_{4}\right)$ & 1.000 & 3.000 & 1.881 & 0.221 & 0.470 \\
Lack of fund and resources $\left(\mathrm{X}_{5}\right)$ & 1.000 & 3.000 & 2.040 & 0.176 & 0.419 \\
Lack of access to buy input $\left(\mathrm{X}_{6}\right)$ & 1.000 & 3.000 & 1.570 & 0.282 & 0.531 \\
Death of animal $\left(\mathrm{X}_{7}\right)$ & 1.000 & 3.000 & 2.300 & 0.341 & 0.584 \\
Reduction in livestock number $\left(\mathrm{X}_{8}\right)$ & 1.000 & 3.000 & 2.462 & 0.329 & 0.574 \\
Shortage of pasture $\left(\mathrm{X}_{9}\right)$ & 1.000 & 3.000 & 2.603 & 0.248 & 0.498 \\
Pest and disease $\left(\mathrm{X}_{10}\right)$ & 1.000 & 3.000 & 2.617 & 0.244 & 0.494 \\
Flood $\left(\mathrm{X}_{11}\right)$ & 1.000 & 3.000 & 1.863 & 0.227 & 0.477 \\
Drought $\left(\mathrm{X}_{12}\right)$ & 2.000 & 3.000 & 2.588 & 0.243 & 0.493 \\
Fire $\left(\mathrm{X}_{13}\right)$ & 1.000 & 3.000 & 1.903 & 0.182 & 0.427 \\
Storm $\left(\mathrm{X}_{14}\right)$ & 1.000 & 2.000 & 1.592 & 0.242 & 0.492 \\
\hline
\end{tabular}

Source: Authors' Computation, 2020.

Table 6 explains the frequency and the relative frequency percentage in each category of variables considered as constraints to PLFS by the farmers in the study area.

Table 6. Categories, frequency, percentages and proportion of the production constraints and the climate related events.

\begin{tabular}{|c|c|c|c|c|}
\hline Variable & Categories & $\begin{array}{l}\text { Frequency per } \\
\text { Category }\end{array}$ & $\begin{array}{c}\text { Rel. Frequency } \\
\text { per Category (\%) }\end{array}$ & $\begin{array}{c}\text { Proportion per } \\
\text { Category }\end{array}$ \\
\hline \multirow[t]{3}{*}{ Shortage of labor $\left(\mathrm{X}_{1}\right)$} & 1 & 32 & 11.552 & 0.116 \\
\hline & 2 & 94 & 33.935 & 0.339 \\
\hline & 3 & 151 & 54.513 & 0.545 \\
\hline \multirow{3}{*}{ Inadequate rainfall $\left(\mathrm{X}_{2}\right)$} & 1 & 81 & 29.242 & 0.292 \\
\hline & 2 & 19 & 6.859 & 0.069 \\
\hline & 3 & 177 & 63.899 & 0.639 \\
\hline \multirow[t]{3}{*}{ Fluctuation in product price $\left(X_{3}\right)$} & 1 & 71 & 25.632 & 0.256 \\
\hline & 2 & 181 & 65.343 & 0.653 \\
\hline & 3 & 25 & 9.025 & 0.090 \\
\hline \multirow[t]{3}{*}{ Lack of storage facilities $\left(\mathrm{X}_{4}\right)$} & 1 & 49 & 17.690 & 0.177 \\
\hline & 2 & 212 & 76.534 & 0.765 \\
\hline & 3 & 16 & 5.776 & 0.058 \\
\hline \multirow[t]{3}{*}{ Lack of fund and resources $\left(\mathrm{X}_{5}\right)$} & 1 & 19 & 6.859 & 0.069 \\
\hline & 2 & 228 & 82.310 & 0.823 \\
\hline & 3 & 30 & 10.830 & 0.108 \\
\hline \multirow{3}{*}{ Lack of access to buy input $\left(X_{6}\right)$} & 1 & 124 & 44.765 & 0.448 \\
\hline & 2 & 148 & 53.430 & 0.534 \\
\hline & 3 & 5 & 1.805 & 0.018 \\
\hline \multirow[t]{3}{*}{ Death of animal $\left(X_{7}\right)$} & 1 & 18 & 6.498 & 0.065 \\
\hline & 2 & 158 & 57.040 & 0.570 \\
\hline & 3 & 101 & 36.462 & 0.365 \\
\hline \multirow{3}{*}{ Reduction in livestock number $\left(\mathrm{X}_{8}\right)$} & 1 & 11 & 3.971 & 0.040 \\
\hline & 2 & 127 & 45.848 & 0.458 \\
\hline & 3 & 139 & 50.181 & 0.502 \\
\hline \multirow[t]{3}{*}{ Shortage of pasture $\left(X_{9}\right)$} & 1 & 1 & 0.361 & 0.004 \\
\hline & 2 & 108 & 38.989 & 0.390 \\
\hline & 3 & 168 & 60.650 & 0.606 \\
\hline \multirow[t]{3}{*}{ Pest and disease $\left(\mathrm{X}_{10}\right)$} & 1 & 1 & 0.361 & 0.004 \\
\hline & 2 & 104 & 37.545 & 0.375 \\
\hline & 3 & 172 & 62.094 & 0.621 \\
\hline \multirow[t]{3}{*}{ Flood $\left(X_{11}\right)$} & 1 & 53 & 19.134 & 0.191 \\
\hline & 2 & 209 & 75.451 & 0.755 \\
\hline & 3 & 15 & 5.415 & 0.054 \\
\hline
\end{tabular}


Table 6. Cont.

\begin{tabular}{ccccc}
\hline Variable & Categories & $\begin{array}{c}\text { Frequency per } \\
\text { Category }\end{array}$ & $\begin{array}{c}\text { Rel. Frequency } \\
\text { per Category (\%) }\end{array}$ & $\begin{array}{c}\text { Proportion per } \\
\text { Category }\end{array}$ \\
\hline Drought $\left(\mathrm{X}_{12}\right)$ & 2 & 114 & 41.155 & 0.412 \\
& 3 & 163 & 58.845 & 0.588 \\
Fire $\left(\mathrm{X}_{13}\right)$ & 1 & 40 & 14.440 & 0.144 \\
& 2 & 224 & 80.866 & 0.809 \\
& 3 & 13 & 4.693 & 0.047 \\
Storm $\left(\mathrm{X}_{14}\right)$ & 1 & 113 & 40.794 & 0.408 \\
& 2 & 164 & 59.206 & 0.592 \\
\hline
\end{tabular}

Note: Category $1=$ Less serious, Category $2=$ Serious, Category $3=$ Most serious. Source: Authors' Computation, 2020.

Table 7 reveals that Principal Component $1\left(P C_{1}\right)$ contributed to 20.671 percent of the variations with an eigenvalue of 2.894 in the variables included in which the cumulative percentage is 20.671 . The $P C_{1}$ is strongly associated with seven of the original variables. This suggests that these seven criteria or variables in the principal component vary together. The $P C_{1}$ increases with a shortage of labor, inadequate rainfall, fluctuation in product price, lack of funds and resources, lack of access to buy input, death of animals, and reduction in livestock number. This suggests that the effect or challenges of climate change on PBLS is greatly influenced by the aforementioned variables, which can be represented as follows: $\left(P C_{1}\right)=0.813 X_{1}+0.516 X_{2}+0.652 X_{3}+0.639 X_{5}+0.548 X_{6}+0.467 X_{7}+$ $0.432 X_{8}$.

Table 7. Principal component analysis.

\begin{tabular}{cccccc}
\hline Variables & $\mathbf{P C}_{\mathbf{1}}$ & $\mathbf{P C}_{\mathbf{2}}$ & $\mathbf{P C}_{\mathbf{3}}$ & $\mathbf{P C}_{\mathbf{4}}$ & $\mathbf{P C}_{\mathbf{5}}$ \\
\hline Shortage of labor $\left(\mathrm{X}_{1}\right)$ & $\mathbf{0 . 8 1 3}$ & 0.272 & 0.027 & -0.020 & 0.076 \\
Inadequate rainfall $\left(\mathrm{X}_{2}\right)$ & $\mathbf{0 . 5 1 6}$ & $\mathbf{0 . 6 7 5}$ & -0.232 & 0.161 & -0.174 \\
Fluctuation in the product price $\left(\mathrm{X}_{3}\right)$ & $\mathbf{0 . 6 5 2}$ & $\mathbf{0 . 4 4 4}$ & -0.207 & -0.109 & -0.226 \\
Lack of storage facilities $\left(\mathrm{X}_{4}\right)$ & 0.145 & 0.079 & $\mathbf{0 . 6 8 8}$ & -0.296 & $\mathbf{0 . 4 9 0}$ \\
Lack of fund and resources $\left(\mathrm{X}_{5}\right)$ & $\mathbf{0 . 6 3 9}$ & $\mathbf{- 0 . 6 3 0}$ & -0.081 & -0.113 & -0.007 \\
Lack of access to buy input $\left(\mathrm{X}_{6}\right)$ & $\mathbf{0 . 5 4 8}$ & $\mathbf{0 . 4 6 1}$ & 0.241 & -0.037 & 0.272 \\
Death of animal $\left(\mathrm{X}_{7}\right)$ & $\mathbf{0 . 4 6 7}$ & -0.320 & 0.195 & 0.399 & -0.040 \\
Reduction in livestock number $\left(\mathrm{X}_{8}\right)$ & $\mathbf{0 . 4 3 2}$ & -0.254 & -0.208 & 0.081 & $\mathbf{0 . 4 1 0}$ \\
Shortage of pasture $\left(\mathrm{X}_{9}\right)$ & 0.180 & -0.256 & 0.149 & $\mathbf{0 . 6 7 2}$ & 0.178 \\
Pest and disease $\left(\mathrm{X}_{10}\right)$ & 0.317 & -0.164 & 0.340 & -0.317 & $\mathbf{- 0 . 4 4 4}$ \\
Flood $\left(\mathrm{X}_{11}\right)$ & 0.336 & $\mathbf{- 0 . 5 0 0}$ & -0.196 & $\mathbf{- 0 . 4 4 9}$ & 0.177 \\
Drought $\left(\mathrm{X}_{12}\right)$ & 0.209 & -0.216 & $\mathbf{0 . 4 5 6}$ & 0.291 & -0.308 \\
Fire $\left(\mathrm{X}_{13}\right)$ & 0.332 & $\mathbf{- 0 . 4 2 4}$ & -0.183 & -0.065 & -0.324 \\
Storm $\left(\mathrm{X}_{14}\right)$ & 0.086 & -0.082 & $\mathbf{- 0 . 5 9 8}$ & 0.112 & 0.265 \\
Eigenvalue & 2.894 & 2.092 & 1.491 & 1.161 & 1.101 \\
Variability $(\%)$ & 20.671 & 14.941 & 10.650 & 8.293 & 7.863 \\
Cumulative $\%$ & 20.671 & 35.612 & 46.262 & 54.556 & 62.419 \\
\hline
\end{tabular}

Source: Authors' Computation, 2020.

Following [25] principle, and [26], five factors (principal components) were extracted based on the result in Table 8, according to the responses of the respondents. Variables with a factor loading of above 0.40 and at $10 \%$ overlapping variance were retained while variables less than 0.40 were not retained.

The $P C_{2}$ contributed to 14.941 percent of the variation according to Table 7 , with an eigenvalue of 2.092 and the cumulative frequency of 35.612 percent. Six variables are strongly associated in $P C_{2}$. This is better explained that $P C_{2}$ increases with inadequate rainfall, fluctuation in product price, lack of access to buy input. However, it decreases with a lack of funds and resources, flood and fire. This indicates that the effect or challenges of climate change on PBLS were significantly influenced by the variables in the equation presented. $\left(P C_{2}\right)=0.675 \mathrm{X}_{2}+0.444 \mathrm{X}_{3}-0.630 \mathrm{X}_{5}+0.461 \mathrm{X}_{6}-0.500 \mathrm{X}_{11}-0.424 \mathrm{X}_{13}$. 
The $P C_{3}$ reported the eigenvalue of 1.491 , the variability and the cumulative percent were 10.650 and 46.262 respectively. The $P C_{3}$ increases with the lack of storage facilities, drought and decreases with storm. This indicates that these variables influence the effect or challenges of climate change on PBLS, and it can be represented as follows: $P C_{3}=0.688 \mathrm{X}_{4}+0.456 \mathrm{X}_{12}-0.598 \mathrm{X}_{14}$. In the same vein, $P C_{4}$ contributed to 8.293 percent of the variations with an eigenvalue of 1.161 in the variables included in which the cumulative percentage is 54.556 percent. The $P C_{4}$ increases with a shortage of pasture, however, it decreases with flooding. This explains that a shortage of pasture and flood influence the effect or challenges of climate change on PBLS. This can be represented as follow: $P C_{4}=0.672 X_{9}-0.449 X_{11}$

Table 8. Bartlett's sphericity test.

\begin{tabular}{ccccc}
\hline Chi-Square (Observed Value) & Chi-Square (Critical Value) & DF & $\begin{array}{c}\text { p-Value } \\
\text { (Two-Tailed) }\end{array}$ & alpha \\
\hline 946.368 & 114.268 & 91 & 0.000 & 0.05 \\
\hline
\end{tabular}

$P C_{5}$ as shown in Table 7 explained that variability percent is 7.863 with an eigenvalue of 1.101 while the cumulative percentage is found to be 62.419. There are three variables which are strongly associated in $P C_{5}$. The explanation for this is that the effect or challenges of climate change on PBLS increases with a lack of storage facilities, reduction in livestock number and, however, decreases with pest and disease. This can be represented as follows: $P C_{5}=0.490 \mathrm{X}_{4}+0.410 \mathrm{X}_{8}-0.444 \mathrm{X}_{10}$.

Tables 8 and 9 show the tests that indicate the suitability and fitness of the PCA employed. The Kaiser-Meyer-Olkin Measure of Sampling Adequacy indicates the proportion of variance of variables that might be caused by underlying factors. High values (close to 1.0) generally show that factor analysis may be useful for the data. On the other hand, if the value is less than 0.50 , the results of the factor analysis will not be useful. Similarly, Bartlett's sphericity test was carried out to test the hypothesis that the correlation matrix. This is an identity matrix, which explains if the variables are unrelated and therefore unsuitable for structure detection. Small values (less than 0.05) of the significance level indicate that factor analysis may be useful with the data. The result from Tables 7 and 8 confirmed that the results from PCA were consistent and fit for the analysis.

Table 9. Kaiser-Meyer-Olkin measure of sampling adequacy.

\begin{tabular}{cc}
\hline Variable & Values \\
\hline Shortage of labor $\left(\mathrm{X}_{1}\right)$ & 0.628 \\
Inadequate rainfall $\left(\mathrm{X}_{2}\right)$ & 0.513 \\
Fluctuation in the product price $\left(\mathrm{X}_{3}\right)$ & 0.730 \\
Lack of storage facilities $\left(\mathrm{X}_{4}\right)$ & 0.312 \\
Lack of fund and resources $\left(\mathrm{X}_{5}\right)$ & 0.555 \\
Lack of access to buy input $\left(\mathrm{X}_{6}\right)$ & 0.760 \\
Death of animal $\left(\mathrm{X}_{7}\right)$ & 0.721 \\
Reduction in livestock number $\left(\mathrm{X}_{8}\right)$ & 0.736 \\
Shortage of pasture $\left(\mathrm{X}_{9}\right)$ & 0.602 \\
Pest and disease $\left(\mathrm{X}_{10}\right)$ & 0.687 \\
Flood $\left(\mathrm{X}_{11}\right)$ & 0.619 \\
Drought $\left(\mathrm{X}_{12}\right)$ & 0.629 \\
Fire $\left(\mathrm{X}_{13}\right)$ & 0.660 \\
Storm $\left(\mathrm{X}_{14}\right)$ & 0.442 \\
KMO & $\mathbf{0 . 6 0 5}$ \\
\hline
\end{tabular}

Source: Authors' Computation, 2020. 
Socio-economics Determinants to Adaptive Capacity among Pasture-based Livestock Farmers in the Study Area: The result from Table 10 revealed that age, other income sources, labor use, own the land and income were statistically significant to adaptive capacity. In other words, adaptive capacity to climate change was determined and influenced by the above-mentioned factors in the study area.

Table 10. Ordered Logit Regression Model.

\begin{tabular}{ccccc}
\hline Adaptive Capacity & Coef. & Std. Err. & $\mathbf{z}$ & $\mathbf{P}>|\mathbf{z}|$ \\
\hline Gender & 0.294 & 0.386 & 0.76 & 0.446 \\
Farming Experience & 0.029 & 0.020 & 1.49 & 0.137 \\
Age & -0.029 & 0.017 & -1.67 & 0.096 \\
Marital Status & -0.230 & 0.213 & -1.08 & 0.279 \\
Education & 0.126 & 0.257 & 0.49 & 0.626 \\
Household Dependent & -0.023 & 0.034 & -0.66 & 0.507 \\
Occupation & -0.123 & 0.316 & -0.39 & 0.696 \\
Other Income Source & 0.401 & 0.201 & 2.00 & 0.045 \\
Labor Use & 1.006 & 0.503 & 2.00 & 0.046 \\
Own the Land & -2.083 & 0.722 & -2.89 & 0.004 \\
TLU & -0.001 & 0.001 & -0.82 & 0.410 \\
Income & 0.000 & 0.000 & 9.22 & 0.000 \\
/cut1 & 0.463 & 1.067 & & \\
/cut2 & 3.694 & 1.149 & &
\end{tabular}

Source: Authors' Computation, 2020. Number of obs = 277; Wald chi2(12) = 102.57; LR chi2(12) = 284.86; Log likelihood $=$-141.07526; Prob $>$ chi2 = 0.0000; Pseudo R2 = 0.5024.

Table 11 shows the predictive margin test explains the outcome for each categories of the adaptive capacity.

Table 11. Predictive margins test.

\begin{tabular}{ccccc}
\hline & Margin & $\begin{array}{c}\text { Delta-method } \\
\text { Std. Err. }\end{array}$ & $\mathbf{z}$ & $\mathbf{P}>|\mathbf{z}|$ \\
\hline predict & & & & \\
1 & 0.407 & 0.019 & 21.32 & 0.000 \\
2 & 0.425 & 0.025 & 16.87 & 0.000 \\
3 & 0.168 & 0.017 & 10.14 & 0.000 \\
\hline
\end{tabular}

Source: Authors' Computation, 2020. Number of obs = 277; Model VCE: OIM; 1._predict: Pr(adaptive capacity==0), predict (pr outcome $(0)$ ); 2._predict: $\operatorname{Pr}($ adaptive capacity==1), predict (pr outcome(1)); 3._predict: $\operatorname{Pr}($ adaptive capacity==2), predict (proutcome $(2))$.

The marginal effect estimates of the results were shown in Table 12, which explains the effect of the margin for each categories of adaptive capacity.

Age was found negatively associated with a coefficient of 0.029 and significantly $(p<0.05)$ influence the adaptive capacity. This implies that an increase in age decreases the adaptive capacity. The age of a farmer plays a significant role in the sustainability of PLFS in the study area. The mean age of the farmers in the study area is 50.473, and this is not surprising as the majority of the farmers in the study area exhibit low outcomes towards high adaptive capacity. This could be attributed to the fact that old farmers are reluctant to adopt new things, measures of adaptive capacity were lacking. This result is supported by [27], who reported that age influence the level of adaptive capacity. 
Table 12. Marginal effect estimates.

\begin{tabular}{ccccc}
\hline Variables & $\begin{array}{c}\text { Marginal Effect for } \\
\text { Y= Low Adaptive } \\
\text { Capacity }\end{array}$ & $\begin{array}{c}\text { Marginal Effect for } \\
\text { Y Moderate Adaptive } \\
\text { Capacity }\end{array}$ & $\begin{array}{c}\text { Marginal Effect for } \\
\text { Y= High Adaptive } \\
\text { Capacity }\end{array}$ & X \\
\hline Gender * & -0.0000853 & 0.0357297 & -0.049087 & 0.906137 \\
Farming Experience & -0.0000734 & 0.0040151 & -0.0044402 & 9.61372 \\
Age & -0.0002242 & 0.0013189 & 0.00191 & 50.4729 \\
Marital Status * & -0.0009519 & -0.0112175 & 0.028839 & 0.606498 \\
Education* & -0.0006024 & 0.1388094 & -0.0343612 & 0.602888 \\
Household Dependent & -0.0002296 & 0.0030022 & 0.0020499 & 6.00722 \\
Occupation & -0.0025792 & 0.3432589 & -0.0335177 & 1.32491 \\
Other Income Source * & 0.0055393 & -0.1183727 & -0.0022053 & 0.592058 \\
Labor Use & 0.0112927 & -0.7057003 & -0.0088369 & 0.194946 \\
Own the Land * & -0.9844422 & 0.1541483 & 0.0584709 & 0.036101 \\
TLU & 0.0000407 & -0.0009255 & 0.0002298 & 69.4152 \\
Income & 0.00000129 & -0.00000216 & -0.00000715 & 19304 \\
\hline
\end{tabular}

$\left({ }^{*}\right) \mathrm{dy} / \mathrm{dx}$ is for discrete change of dummy variable from 0 to 1. Source: Authors' Computation, 2020.

The other source of income was positively associated (coefficient of 0.401) and statistically significant, thus influencing adaptive capacity. Farmers who engage in off-farm activities apart from earning income in farming tend to increase the adaptive capacity as the farmer would be able to afford facilities needed such as irrigation facilities among others. In the same train of thought, the level of income influences adaptive capacity. Income generated from agricultural activities also determines the level of adaptive capacity. The higher the income generated, the more likely a farmer tends to increase the level of adaptive capacity [28], reported similar results, that level of income in livestock farming determines the level of adaptive capacity among rural household farming in Ethiopia.

The use of labor was positively correlated and significantly $(p<0.05)$ influenced the level of adaptive capacity in the study area. The maximum number of labor use as found in Table 1, was three laborers, however, it was established that farmers with more labor use have a higher probability to increase the level of adaptive capacity. The reason could be that the farmer has more helping hands to adopt and carry out certain activities on the farm to increase the level of adaptive capacity. Activities such as farm management practices, implementation of irrigation, windbreaks among many others. This could be referred to as adaptation through human assets as explained by [29].

The landowner is another factor that determines the level of adaptive capacity in the study area. Owning the land was negatively associated with a coefficient of -2.083 and statistically significant. The reason for this result is that the knowledge and experience of the landowners determine the adoption of natural resources management and the level of adaptive capacity. This was supported by [23], who reported that landownership is likely to influence adoption if the innovation requires investments tied to the land.

Figure 2 shows the predictive margin graph of adaptive capacity used by pasture-based livestock farmers in the study area in the face of climate-related events. The high adaptive capacity is seen to be relatively low, followed by the low adaptive capacity. This graph is better explained in Table 2, where the percentage of high adaptive capacity, low adaptive and moderate adaptive capacity were given as $16.2 \%, 40.1 \%$ and $43.7 \%$ respectively. 


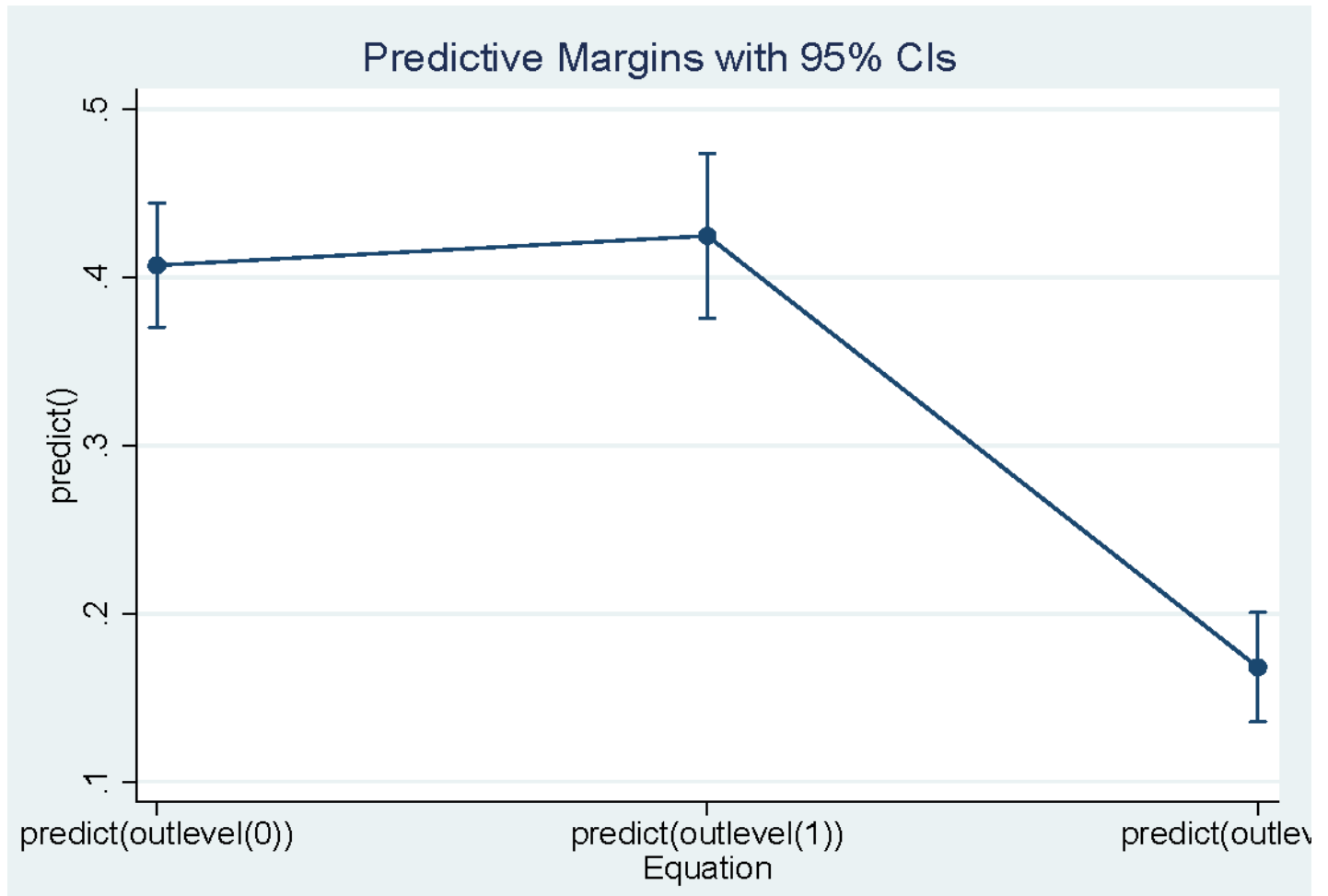

Figure 2. Predictive margins graph.

\section{Conclusions}

The results explained the production constraints and the climate related events which could possibly influenced the sustainability of pastured-based livestock farmers in South Africa. The study outlined age of the farmers, other sources of income from agriculture, the use of labor, and landowners, were significantly influenced the adaptive capacity of pasture-based livestock farmers. By implication, for pasture-based farmers to improve on adaptive capacity, the policy should be targeted towards the highlighted influenced factors. In the same manner, this translates to enhance the sustainable development goal (SDGs) of the united nation (Goal 1,2,3 and 12), as well as vision 2030 of the National Development Plan (NDP) which aims to eliminate poverty and reduce inequality, achievable through agriculture. This can also help the policymakers, department of agriculture, the researchers and other stakeholder concerns towards improving the adaptive capacity of PLFS, especially in the study area.

Author Contributions: For research articles with several authors, a short paragraph specifying their individual contributions must be provided. The following statements should be used "Conceptualization, O.S.O. and T.T.R.; Methodology, O.S.O.; software, O.S.O.; validation, O.S.O., M.A.A. and T.T.R.; formal analysis, O.S.O.; investigation, O.S.O., Rubhara, T.T.R. and M.A.A.; resources, M.A.A.; data curation, M.A.A.; writing-original draft preparation, O.S.O. and T.T.R.; writing-review and editing, O.S.O.; M.A.A. and T.T.R.; visualization, O.S.O.; M.A.A. and T.T.R.; supervision, M.A.A.; project administration, M.A.A.; funding acquisition, M.A.A. All authors have read and agreed to the published version of the manuscript.", please turn to the CRediT taxonomy for the term explanation. Authorship must be limited to those who have contributed substantially to the work reported.

Funding: The research was funded by the Agricultural Research Council, Climate Change Collaboration Centre. This is a research collaboration entity for UNISA, University of Pretoria and Agricultural Research Council of South Africa.

Acknowledgments: The authors acknowledge the anonymous reviewers for improving the quality of this paper. The authors appreciate all the participants who contributed to this research, including ARC, University of Pretoria and University of South Africa.

Conflicts of Interest: The authors declare there is no conflict of interest. 


\section{References}

1. Meisnner, H.H.; Scoltz, M.M.; Engelbrecht, F.A. Sustainability of the South African Livestock Sector towards 2050 Part 2: Challenges, changes and required implementations. S. Afr. J. Anim. Sci. 2013, 43, $298-318$. [CrossRef]

2. Nardone, A. Evolution of livestock production and quality of animal products. In Proceedings of the 39th Annual Meeting of the Brazilian Society of Animal Science, Recife Pernambuco, Brazil, 29 July-2 August 2002; pp. 486-513.

3. Nardone, A.; Ronchi, B.; Lacetera, N.; Ranieri, M.S.; Bernabucci, U. Effects of climate changes on animal production and sustainability of livestock systems. Livest. Sci. 2010, 130, 57-69. [CrossRef]

4. Popkin, B.M. The dynamics of the dietary transition in the developing world. In The Nutrition Transition: Diet and Disease in the Developing World, Food Science and Technology International Series; Caballero, B., Popkin, B.M., Eds.; Academic Press: London, UK, 2002; pp. 111-129.

5. IPCC (Intergovernmental Panel on Climate Change: AR4). The Intergovernmental Panel on Climate Change 4th Assessment Report; Jackson Institute, University College: London, UK; Available online: www.ipcc.ch/ (accessed on 10 December 2007).

6. Rojas-Downing, M.M.; Nejadhashemi, A.P.; Harrigan, T.; Woznick, S.A. Climate change and livestock: Impacts, adaptation, and mitigation. Clim. Risk Manag. 2017, 16, 145-163. [CrossRef]

7. Cederberg, C.; Stadig, M. System expansion and allocation in life cycle assessment of milk and beef production. Int. J. Life Cycle Assess. 2003, 83, 50-356. [CrossRef]

8. Asem-Hiablie, S.; Battagliese, T.; Stackhouse-Lawson, K.; Rotz, C.N. A life cycle assessment of the environmental impacts of a beef system in the USA. Int. J. Life Cycle Assess. 2019, 24, 441-455. [CrossRef]

9. Mendelsohn, R. The Impact of Climate Change on Agriculture in Developing Countries. J. Nat. Resour. Policy Res. 2008, 1, 5-19. [CrossRef]

10. Department of Agriculture Forestry and Fisheries, (DAFF). Abstract of Agricultural Statistics; Department of Agriculture, Forestry and Fisheries: Pretoria, South Africa, 2018.

11. Department of Agriculture Forestry and Fisheries, (DAFF). Abstract of Agricultural Statistics; Department of Agriculture, Forestry and Fisheries: Pretoria, South Africa, 2019.

12. Conner, D.S.; Hamm, M.W.; Smalley, S.B.; Williams, D. Pasture-Based Agriculture: Opportunities for Public Research Institutions. C.S Mott Group for Sustainable Food Systems. Michgan State University, Michgan. 2009. Available online: https://www.canr.msu.edu/foodsystems/uploads/files/AITFS_proceedings. pdf (accessed on 2 February 2020).

13. McDonald, C.K.; van Oudtshoorn, F.P. Challenges for emerging livestock farmers in Limpopo province, South Africa. Afr. J. Range Forage Sci. 2008, 25, 71-77. [CrossRef]

14. Khapayi, M.; Celliers, P.R. Factors limiting and preventing emerging farmers to progress to commercial agricultural farming in the King William's Town area of the Eastern Cape Province, South Africa. S. Afr. Jnl. Agric. Ext. 2016, 44, 25-41. [CrossRef]

15. Mapiye, C.; Chimonyo, M.; Dzama, K.; Raats, J.G.; Mapekula, M. Opportunities for improving Nguni cattle production in the smallholder farming systems of South Africa. Livest. Sci. 2009, 124, 196-204. [CrossRef]

16. Dzama, K. Is the Livestock Sector in Southern Africa Prepared for Climate Change; Policy Briefing 153 November; Southern African Institute of International Affairs (SAIIA): Pretoria, South Africa, 2016.

17. Muller, M.; Schreiner, B.; Smith, L.; van Koppen, B.; Sally, H.; Aliber, M.; Cousins, B.; Tapela, B.; van der Merwe-Botha, M.; Karar, E.; et al. Water security in South Africa. In Development Planning Division; Working Paper Series No.12; DBSA: Midrand, South Africa, 2009.

18. World Initiative for Sustainable Pastoralism (WISP). Building climate change resilience for African livestock in sub-Saharan Africa. In A Programme of the International Union for Conservation of Nature; Eastern and Southern Africa Regional Office: Nairobi, Kenya, 2010.

19. Mthembu, N.N.; Zwane, E.M. The adaptive capacity of smallholder mixed-farming systems to the impact of climate change: The case of KwaZulu-Natal in South Africa. Jamba 2017, 9, 1-9. [CrossRef] [PubMed]

20. Fussel, A. Adaptation planning for climate change: Concepts, assessment approaches, and key lessons. Sustain. Sci. 2007, 2, 265-275. [CrossRef]

21. Maltou, R.; Bahta, Y. Factors influencing the resilience of smallholder livestock farmers to agricultural drought in South Africa: Implication for adaptive capabilities. Jamba 2019, 11. [CrossRef] [PubMed] 
22. Oduniyi, O.S.; Tekana, S.S. Establishing the nexus between climate change adaptation strategy and smallholder farmers' food security status in South Africa: A bi-casual effect using instrumental variable approach. Cogent Soc. Sci. 2019, 5. [CrossRef]

23. Oduniyi, O.S. Implication of Climate Change on Livelihood and Adaptation of Small and Emerging Maize Farmers in the North West Province of South Africa. Ph.D. Thesis, University of South Africa, Pretoria, South Africa, 2018.

24. Olawuyi, S.O. Investigating Benefits Effects of Social Networks among Rural Farmers: Implications on Households' Food and Nutrition Security in Oyo State, Nigeria. Int. J. Econ. Res. 2018, 15, 765-775.

25. Kaiser, H.F. The application of electronic computers to factor analysis. Educ. Psychol. Meas. 1960, 20, 141-151. [CrossRef]

26. Madukwe, M.C. Multivariate Analysis for Agricultural Extension Research. In Research Methods in Agricultural Extension in Nigeria; Terry, A.O., Ed.; 2004; pp. 206-236.

27. Klein, R.J.T.; Midgley, G.F.; Preston, B.L.; Alam, M.; Berkhout, F.G.H.; Dow, K.; Shaw, M.R. Adaptation opportunities, constraints, and limits. In Climate Change 2014: Impacts, Adaptation, and Vulnerability. Part A: Global and Sectoral Aspects. Contribution of Working Group II to the Fifth Assessment Report of the Intergovernmental Panel on Climate Change; Field, C.B., Barros, V.R., Dokken, D.J., Mach, K.J., Mastrandrea, M.D., Bilir, T.E., Chatterjee, M., Ebi, K.L., Estrada, Y.O., Genova, R.C., et al., Eds.; Cambridge University Press: Cambridge, UK; New York, NY, USA, 2014; pp. 899-943.

28. Berhe, M.; Hoag, D.; Tesfay, G.I. The effects of adaptation to climate change on income of households in rural Ethiopia. Pastoralism 2017, 7. [CrossRef]

29. Mhlanga-Ndlovu, F.N.; Nhamo, G. Small-Scale Farmers Associations' adaptive capacity to climate change in Swaziland sugarcane industry. Jamba 2019, 11. [CrossRef] [PubMed]

(C) 2020 by the authors. Licensee MDPI, Basel, Switzerland. This article is an open access article distributed under the terms and conditions of the Creative Commons Attribution (CC BY) license (http://creativecommons.org/licenses/by/4.0/). 